\title{
Structural and Mechanical Behavior of Layered Zirconium Phosphonate as a Distributed Phase in Polycaprolactone
}

\author{
Benjamin R. Furman, ${ }^{1}$ Stephen T. Wellinghoff, ${ }^{1}$ Richard M. Laine, ${ }^{2}$ \\ Kwai S. Chan, ${ }^{1}$ Daniel P. Nicolella, ${ }^{1}$ H. Ralph Rawls ${ }^{3}$ \\ ${ }^{1}$ Chemistry and Chemical Engineering Division, Southwest Research Institute, San Antonio, Texas 78238 \\ ${ }^{2}$ Materials Science and Engineering Department, University of Michigan, Ann Arbor, Michigan 48109 \\ ${ }^{3}$ Department of Restorative Dentistry, University of Texas Health Science Center at San Antonio, \\ San Antonio, Texas 78229
}

Received 2 September 2008; accepted 15 March 2009

DOI 10.1002/app.30501

Published online 16 June 2009 in Wiley InterScience (www.interscience.wiley.com).

\begin{abstract}
Mixed-surface octyl/methoxyundecyl $\alpha$-zirconium phosphonates (ZrPs) were investigated as distributed nanoscale fillers, in concentrations up to $50 \% \mathrm{w} / \mathrm{w}$, for the purpose of increasing the elastic modulus and yield strength of polycaprolactone (PCL) without a meaningful reduction of its ductility. The volumetric nanoparticle loadings were estimated to be over $70 \%$ higher than those in nanocomposites with comparable weight fractions of nanoclay. The mechanical properties of the $\mathrm{ZrP} / \mathrm{PCL}$ nanocomposite were evaluated with tensile, flexural, and dynamic mechanical testing methods. Nanocomposites containing $5 \% \mathrm{w} / \mathrm{w} \mathrm{ZrP}$ showed significant increases in both the ten-
\end{abstract}

sile yield stress and elastic modulus without any loss of ductility versus the unfilled polymer. Layer delamination from the $\mathrm{ZrP}$ tactoids was minimal. Kinetic barriers and the strong interlayer attraction between the $\mathrm{ZrP}$ surfaces limited intercalative penetration of the $\mathrm{ZrP}$ tactoids. $\mathrm{ZrP}$ loadings of $20 \% \mathrm{w} / \mathrm{w}$ or more resulted in the agglomeration of tactoids, leading to defect structures with a loss of strength and, at the highest loading, ductility. ( 2009 Wiley Periodicals, Inc. J Appl Polym Sci 114: 993-1001, 2009

Key words: interpenetrating networks (IPN); miscibility; nanocomposites; nanolayers; polyesters

\section{INTRODUCTION}

Ductile thermoplastic additives have been shown to impart as much as an 8-fold improvement in fracture toughness to brittle thermosets while causing moderate reductions in the glass-transition temperature $\left(T_{g}\right)$ and elastic modulus. ${ }^{1,2}$ For applications in dental restoration, it is highly desirable to toughen a thermosetting system without compromising its elastic modulus. Unfortunately, many thermoplastic polymers with attractive solubility parameters have especially low elastic moduli. Therefore, a means of reinforcing a low-stiffness polyester has been sought for the long-term purpose of toughening acrylic thermosetting resins.

High-aspect, platy nanoparticles or nanoplatelets, such as those derived from layered silicates (LSs), have been studied extensively in the reinforcement of polymeric structures. ${ }^{3-17}$ Substantial potential for plastic deformation between nanoplatelets is indicated when the polymer successfully intercalates the nanoplatelet galleries and crystallizes upon solidifi-

Correspondence to: B. R. Furman (bfurman@swri.org).

Contract grant sponsor: National Institute for Dental and Craniofacial Research; contract grant number: 5P01DE11688.

Journal of Applied Polymer Science, Vol. 114, 993-1001 (2009) (c) 2009 Wiley Periodicals, Inc. cation from the melt. ${ }^{17}$ Both intercalated and exfoliated systems of LS can dramatically increase elastic moduli in semicrystalline thermoplastics. ${ }^{4}$ The theoretical upper boundary for the elastic modulus is given by a homogeneous dispersion of an exfoliated filler at a low concentration $(\leq 12 \% \mathrm{v} / \mathrm{v})^{11,18}$ at which the degree of stiffening dramatically exceeds that expected from simple rules of mixture. ${ }^{19}$ As the LS content exceeds $4 \% \mathrm{v} / \mathrm{v}$, the rate of the increase in the elastic modulus versus the loading slows because of an increase in the relative proportion of the intercalated filler. ${ }^{20}$

Nonsiliceous nanoplatelets have also been investigated in polymer nanocomposites. In particular, Sue and coworkers ${ }^{21-23}$ studied $\alpha$-zirconium phosphates as reinforcements for epoxy resin. Mechanically, the materials showed no improvement in fracture toughness over the unmodified epoxy because of facile delamination along the $\alpha$-zirconium phosphonate (ZrP) lamellar interface. ${ }^{22}$ However, the tensile strength and elastic modulus were increased significantly, whereas the material's overall ductility was maintained; this indicated a high work of fracture.

Ether-functional $\mathrm{ZrP}$ materials were first introduced by us $^{24}$ as candidate fillers for thermoplastic polyesters. As part of this earlier investigation, the thermodynamics of the polymer host/guest interactions were explored by computer simulation. It has been proposed that the specific surface interactions 
of the inorganic layers within various host polymers are critically important to the enhancement of the elastic modulus because thermodynamic interactions govern both the means of polymer confinement and the polymer morphology within the interlayer galleries. $5,12,17$ The outcome of our work $^{24}$ suggested that linear polyesters, such as polycaprolactone (PCL), should have favorable energies of mixing, principally through dipole-dipole interactions, by intercalating $\mathrm{ZrP}$ systems with mixed octyl and 11methoxyundecyl (MOUD) phosphonate ligands in a $1: 1$ ratio.

PCL is a highly crystalline polymer with high ductility and a low elastic modulus. The material is easily capped with diverse organic functionalities, ${ }^{25}$ and its adaptability makes it attractive for eventual inclusion in toughened dental acrylic polymers.

Octyl/MOUD ZrP was synthesized with slight modification of the conventional method; ${ }^{26}$ layered nanoplatelets were produced in a relatively high yield with few dislocation defects. PCL nanocomposites were formulated with a range of filler levels to determine the effects of the particle loading on the static and dynamic mechanical properties. The structure-property relationships are discussed accordingly.

\section{EXPERIMENTAL}

Reagents and solvents were used as purchased, without further purification, unless otherwise noted. PCL pellets (number-average molecular weight $=$ $80,000 \mathrm{~g} / \mathrm{mol}$; Aldrich, St. Louis, MO) were cryogenically ground into a coarse powder (1-mm grain size) with a Retsch (Newtown, PA) mill by the direct addition of liquid nitrogen. Room temperature was $20 \pm 1^{\circ} \mathrm{C}$. 11-Methoxyundecyl phosphonic acid was prepared as previously described by Furman. ${ }^{27}$

\section{Synthesis of the octyl/MOUD ZrP nanoplatelets}

In a typical reaction, in air, $4.3 \mathrm{mmol}$ of $\mathrm{ZrOCl}_{2}$. $8 \mathrm{H}_{2} \mathrm{O}$ (98\%; Aldrich) was added to $30 \mathrm{~mL}$ of deionized water in a polytetrafluoroethylene digestion vessel (Savillex Corp., Minnetonka, MN) equipped with a polytetrafluoroethylene condenser and a magnetic stirring bar. Concentrated aqueous HF $(48 \%$ $\mathrm{w} / \mathrm{w}$; Aldrich) was then added so that $[\mathrm{F}] /[\mathrm{Zr}]$ equaled 8 . After a few minutes of stirring, octylphosphonic acid (98\%; Lancaster; $6.5 \mathrm{mmol}$ ) and MOUDOA $(6.5 \mathrm{mmol})$ powders were added to the previously acidified solution so that $[\mathrm{P}] /[\mathrm{Zr}]$ equaled 3. An additional $35 \mathrm{~mL}$ of water was added, and the two-phase reaction mixture was heated over a $70^{\circ} \mathrm{C}$ oil bath for 1 week with stirring. The final product was isolated by filtration and washed with $120 \mathrm{~mL}$ of ethanol; a poly (ether sulfone) membrane-type fil- ter with a pore size of $0.2 \mu \mathrm{m}$ was used. The yield was $91 \%$.

Approximately $2.2 \mathrm{~g}$ of $\mathrm{ZrP}$ was dispersed in 100 $\mathrm{mL}$ of ethanol containing $0.3 \mathrm{~g}$ of a $20 \%$ tetraethyl ammonium hydroxide (TEAH) solution to neutralize $\equiv \mathrm{PO}^{-}$groups present from deprotonated dangling bonds along the edges of the nanoplatelets. The suspension was sonicated for a total of $20 \mathrm{~min}$ with a horn-type sonicator with $39-\mathrm{W}$ power delivery (Microson XL2020, Misonix, Inc., Farmingdale, NY). After sonication, the suspended material was centrifuged, and the supernatant was poured away. The treated $\mathrm{ZrP}$ was dried in a vacuum oven at $120^{\circ} \mathrm{C}$ for $12 \mathrm{~h}$.

\section{Preparation of the experimental composites: the counter-rotating centrifuge method}

A dry mixture of the ground PCL, totaling $4 \mathrm{~g}$, was formulated with up to $20 \% \mathrm{w} / \mathrm{w}$ TEAH-treated $\mathrm{ZrP}$ by agitation in a SpeedMixer (Flack Tek, Landrun, SC) at $1800 \mathrm{rpm}$. A small amount of acetone (ca. 2 $\mathrm{mL}$ ) was then added to soften the polymer. The softened mixture was remixed with the SpeedMixer at $3500 \mathrm{rpm}$ for a total of $5 \mathrm{~min}$. The solvated composite was then dried at $60^{\circ} \mathrm{C}$ under a house vacuum. Finally, the composite was heated to $120^{\circ} \mathrm{C}$ and quickly transferred to the SpeedMixer for final blending at $3500 \mathrm{rpm}$.

\section{Compounding extrusion method}

The ground PCL resin was dry-mixed with $\mathrm{ZrP}$ for 2 min at $2400 \mathrm{rpm}$ with the SpeedMixer. Melt compounding was performed with a twin-screw extruder (MiniLab microcompounder, Thermo-Haake, Waltham, MA) with a rotational speed of 30-50 rpm. The screw and backflow chambers were filled with a total of $6 \mathrm{~g}$ of material. The free-flowing dry premix was added directly to the extruder hopper and circulated through the screw and backflow chambers at $110^{\circ} \mathrm{C}$ for $25 \mathrm{~min}$. Fibers were drawn from the extruder in air through a $1.25-\mathrm{mm}$ orifice onto a motorized spool, and the remaining material was recovered from the flow chambers after thermal quenching.

\section{Characterization: tensile mechanical testing}

Extruded fibers were cut into sections approximately $15 \mathrm{~cm}$ long. The specimens were individually mounted onto a Sintech 20/G electromechanical test frame (MTS Systems, Eden Prairie, MN) via rubberized pneumatic grips. The specimens were tested in uniaxial tension with a 102-mm gage length, a 111-N load cell, and a $508 \mathrm{~mm} / \mathrm{min}$ crosshead speed. Ductile specimens were extended until the limits of the 
test frame were reached. The temperature and relative humidity of the ambient test environment were $25^{\circ} \mathrm{C}$ and $35 \%$, respectively.

\section{Flexural mechanical testing}

Rectangular beam specimens, nominally $2 \times 2 \times 52$ $\mathrm{mm}^{3}$, were formed from the previously extruded fibers. The fibers were compressed in a stainless steel slot mold under an external load of 20,000 N while being heated to $135^{\circ} \mathrm{C}$. The molded specimens were released and cut in half before testing, in threepoint bending, with the Sintech $20 / G$ electromechanical test frame and a support span of $18 \mathrm{~mm}$.

Single-edge notched beams (SENBs; ASTM E 1820) were prepared by precracking of the standard test beams to a nominal depth of $1 \mathrm{~mm}$ with a new razor blade. They were tested under three-point bending to failure with a crosshead speed of $5 \mathrm{~mm} / \mathrm{min}$ and a 111-N load cell. Elastic moduli were determined for unnotched specimens with the same crosshead speed and an 11-N load cell.

\section{Dynamic mechanical analysis (DMA)}

Rectangular beam specimens, nominally $2 \times 2 \times 18$ $\mathrm{mm}^{3}$, were tested in three-point bending with a DMA 7 (PerkinElmer, Waltham, MA) with a test span of $15 \mathrm{~mm}$. A fixed load of $110 \mathrm{mN}$ and a dynamic load of $100 \mathrm{mN}$ were applied. For temperature scans, the dynamic loading frequency was 1 Hz. Frequency scans were performed from 1 to 51 $\mathrm{Hz}$ at $21^{\circ} \mathrm{C}$. The specimen chamber was purged continuously with nitrogen gas at a flow rate of $30 \mathrm{~mL} /$ min. An internal block temperature of $-52^{\circ} \mathrm{C}$ was maintained by refrigeration.

\section{Differential scanning calorimetry (DSC)}

Thermal scans were performed with a Pyris 1 differential scanning calorimeter (PerkinElmer) with a nitrogen purge flow of $30 \mathrm{~mL} / \mathrm{min}$. Specimens (10$20 \mathrm{mg}$ ) of PCL and ZrP-filled PCL were tested in triplicate with a thermal cycle from 20 to $120^{\circ} \mathrm{C}$ at a ramp rate of $40^{\circ} \mathrm{C} / \mathrm{min}$.

\section{Thermogravimetric analysis (TGA)/dynamic thermal analysis}

Thermal analysis was performed with a Q-series SDT-600 differential scanning calorimeter/thermogravimetric analyzer (TA Instruments, New Castle, DE). The samples, weighing approximately $10 \mathrm{mg}$ each, were preconditioned at $100^{\circ} \mathrm{C}$ under a 100 $\mathrm{mL} / \mathrm{min}$ flow of dry air. Burnout experiments were conducted in air with a temperature ramp from 100 to $1100^{\circ} \mathrm{C}$ at a ramp rate of $10^{\circ} \mathrm{C} / \mathrm{min}$. The materials were then held at $1100^{\circ} \mathrm{C}$ for $30 \mathrm{~min}$ to ensure complete oxidation.

\section{X-ray diffraction (XRD)}

XRD patterns were obtained with a D8 Advance analytical diffractometer (Bruker AXS GmbH, Karlsruhe, Germany) equipped with a $\mathrm{Cu} \mathrm{K \alpha}$ radiation source, a 1.0-mm fixed-divergence slit, a Johansson focusing monochromator, and a standard scintillation detector with a $0.1-\mathrm{mm}$ slit. The source was operated with an acceleration voltage of $36 \mathrm{kV}$ and a filament current of $20 \mathrm{~mA}$. The scan rate was set to $5 \mathrm{~s} / \mathrm{step}$ with a step size of $\theta=0.025^{\circ}$.

\section{Transmission electron microscopy (TEM)}

Electron micrographs were obtained on a JEOL 1230 apparatus (JEOL, Ltd., Tokyo, Japan) equipped with an $\mathrm{LaB}_{6}$ electron gun and operated at $80 \mathrm{kV}$. Images were acquired with a charged coupling device camera system (AMT Corp., Danvers, MA). A catalase crystal standard (Ted Pella, Redding, CA) was also imaged to provide an internal reference $d$-spacing of $8.75 \mathrm{~nm}$. Fast Fourier transform filtering of the images was performed with the ImageJ image-processing package from the National Institutes of Health (http://rsb.info.nih.gov/ij). Simulated diffraction spots in the Fourier power spectra were compared with those of the catalase crystal, with a known spacing, to yield experimental $d$-spacings for the nanoplatelet layers.

\section{RESULTS AND DISCUSSION}

\section{ZrP composition}

Layered octyl/MOUD ZrP was produced through a $\mathrm{ZrF}_{6}{ }^{2-}$-mediated condensation reaction similar to that used by Alberti et al. ${ }^{26}$ The isolated material had an (001) layer spacing of $28.4 \AA$, as determined by XRD. The ceramic yield $(52.7 \% \mathrm{w} / \mathrm{w})$ was within $1 \%$ of the theoretical value $\left[51.7 \% \quad \mathrm{w} / \mathrm{w} \quad \mathrm{Zr}\left(\mathrm{O}_{3}-\right.\right.$ $\left.\mathrm{POH})_{2}\right]$, which was within the experimental error.

The theoretical density $(\rho)$ of octyl/MOUD ZrP could be deduced from the monoclinic unit cell values with the following formula:

$$
\rho=\frac{Z M}{N(a \times b) c \sin \beta}
$$

where $Z$ is the number of formula units per unit cell; $M$ is the formula weight; $N$ is Avogadro's number; $a, b$, and $c$ are lattice parameters; and $\beta$ is the angle between the $a$ and $b$ unit cell axes. $a$ and $b$ for organic zirconium phosphonates could be estimated from zirconium bisphenyl phosphonate: $a=$ $9.0985 \AA$ and $b=5.4154 \AA\left(\beta=101.333^{\circ}\right) .{ }^{28}$ 


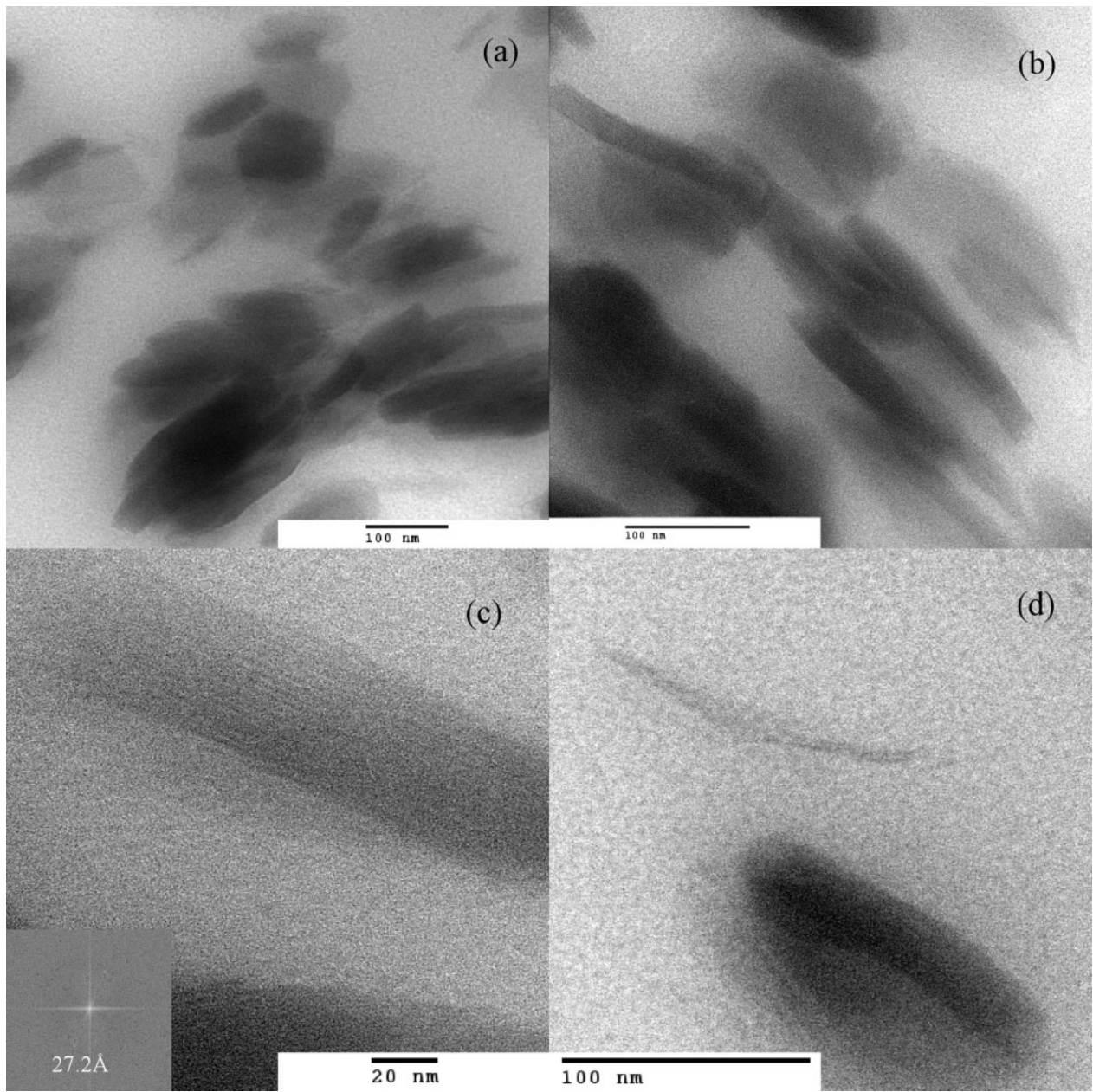

Figure 1 TEM micrographs of TEAH-treated $\mathrm{ZrP}$ after speed mixing in molten PCL: (a) hexagonal tactoid faces, (b) tactoid edges (ca. $20 \times 100 \mathrm{~nm}^{2}$ ), (c) resolved tactoid layers, and (d) a delaminated layer pair viewed edge-on.

Meanwhile, $c$ was equal to $2 d_{(001)}=56.8 \AA$. Each unit cell contained four formula units ${ }^{29}$ with an average composition of $\mathrm{CH}_{3}\left(\mathrm{CH}_{2}\right)_{7} \mathrm{PO}_{3} \mathrm{ZrO}_{3}\left(\mathrm{CH}_{2}\right)_{11}$ $\mathrm{OCH}_{3}$, which had a formula weight of $547.72 \mathrm{~g} / \mathrm{mol}$. Therefore, the density of octyl/MOUD ZrP was estimated to be $1.33 \mathrm{~g} / \mathrm{cm}^{3}$.

Edge charges from dangling phosphoryl anions pose a potential kinetic barrier to polymer intercalation in $\mathrm{ZrP}$. Therefore, TEAH pretreatment was performed on all $\mathrm{ZrP}$ materials before blending with PCL.

\section{Nanocomposite morphology}

After TEAH pretreatment, the $\mathrm{ZrP}$ powder was blended at $20 \% \mathrm{w} / \mathrm{w}$ in PCL (weight-average molecular weight $=80,000 \mathrm{~g} / \mathrm{mol}$ ) via the SpeedMixer method. The composite showed limited evidence of delamination under TEM (Fig. 1), although the vast majority of the layers remained bound together in the tactoids (Fig. 2). XRD showed an average interlayer $d$-spacing of $27.8 \AA$ with no indication of polymer intercalation or exfoliation (Fig. 3). The majority

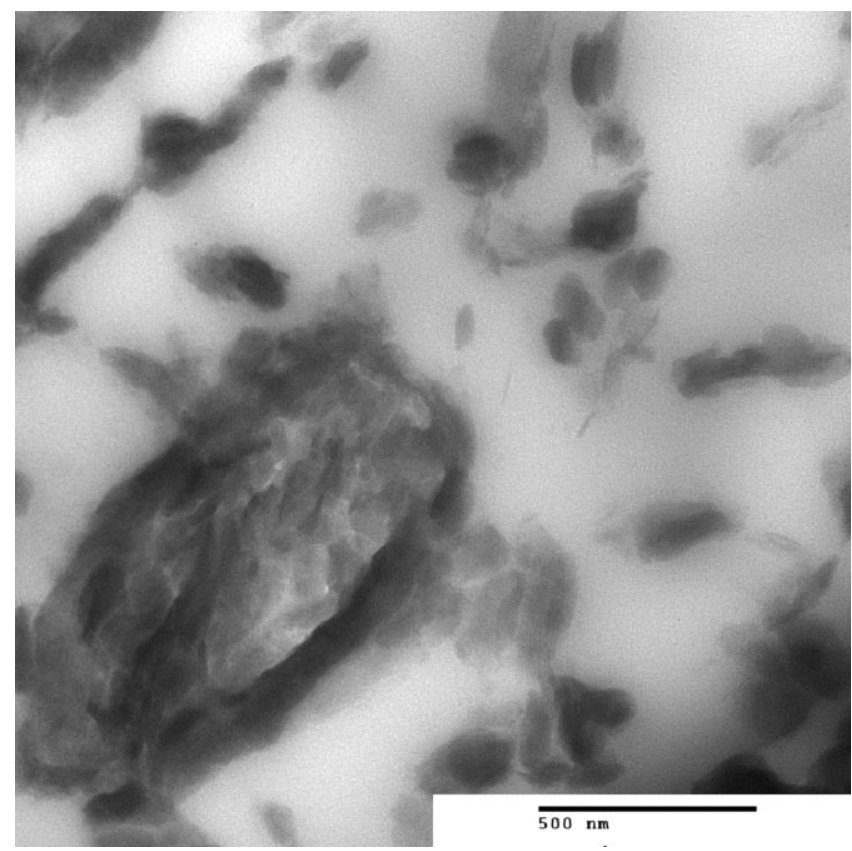

Figure 2 Agglomeration of tactoids at the $20 \% \mathrm{w} / \mathrm{w}$ level in extruded $\mathrm{ZrP} / \mathrm{PCL}$. 


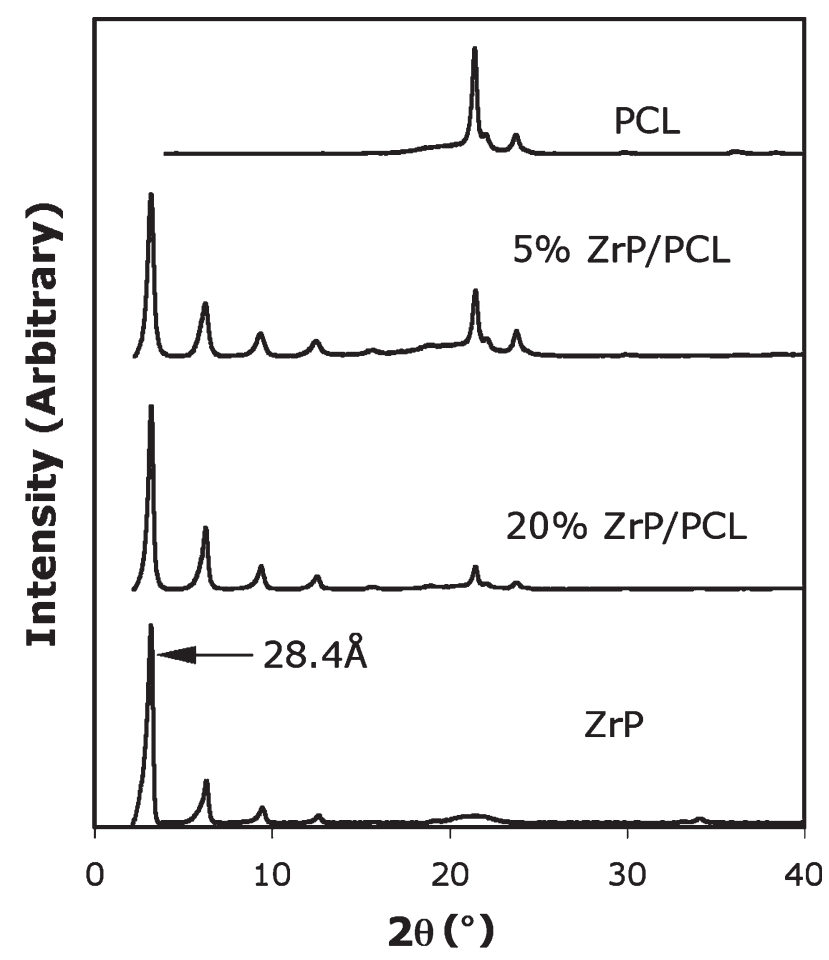

Figure $3 \mathrm{XRD}$ patterns for TEAH-treated $\mathrm{ZrP}$ and $\mathrm{ZrP} /$ PCL nanocomposites.

of nanoplatelets remained clustered into tactoids containing 7-10 individual layers with dimensions of about $20 \times 100 \mathrm{~nm}^{2}$ [Fig. 1(b)]. Fast Fourier transform filtering was applied to four different high-resolution TEM images, providing a conservative estimate for the average intralayer $d$-spacing of $27.2 \AA$ A. A representative image used in the measurement of the spacing is provided in Figure 1(c), with the simulated diffraction pattern shown in the inset. Measurement by this method suffers from situational variability due to the uncontrolled viewing axis. If the $\mathrm{ZrP}$ nanoplatelets had been completely delaminated, then a typical nanoplatelet would have had an aspect ratio of 30 or more.

The same ZrP/PCL composition, when extruded, showed a similarly small number of delamination events. However, drawing, peeling, and thinning of some tactoids occurred (see Fig. 4). Once again, no exfoliation could be detected by XRD (see Fig. 3). A comparison of the integrated $\mathrm{ZrP}$ peak intensities with respect to the internal PCL standard did not show any extinction of the $\mathrm{ZrP}$ layer correlations.

The volumetric loadings of $\mathrm{ZrP}$ (density $\approx 1.33 \mathrm{~g}$ / $\mathrm{cm}^{3}$ ) were over $70 \%$ higher than those reported for organically modified clays having densities near 2.3 $\mathrm{g} / \mathrm{cm}^{3}$ at equivalent weight fractions. ${ }^{30-32}$

Figure 2 shows an increase in agglomeration due to a $\mathrm{ZrP}$ loading of $20 \% \mathrm{w} / \mathrm{w}$ in PCL. Dispersed tactoids with distorted outer layers are also visible, many of which were drawn into longer forms. Micrometer-sized agglomerates in LS/polymer systems are insufficiently loaded to cause delamination under an applied stress, and this results in embrittlement of the composites. ${ }^{33,34}$ Large agglomerates in $\mathrm{ZrP} / \mathrm{PCL}$ may counteract any property improvements gained from elongation and thinning of the tactoids.

The extruded ZrP/PCL formulations exhibited an intralayer $d$-spacing of $27.9 \AA$, as determined by XRD. This value is very close to the XRD measurement of $28.4 \AA$ for the isolated ZrP (Fig. 3). Aggregate cohesion was evident in PCL from both the XRD results and the observation by TEM that the $\mathrm{ZrP}$ tactoids underwent considerable distortion without intercalation during the melt-compounding process [Fig. 4(b)].

Individual layers, or small groups of layers, appeared to be sheared or split away at the edges as

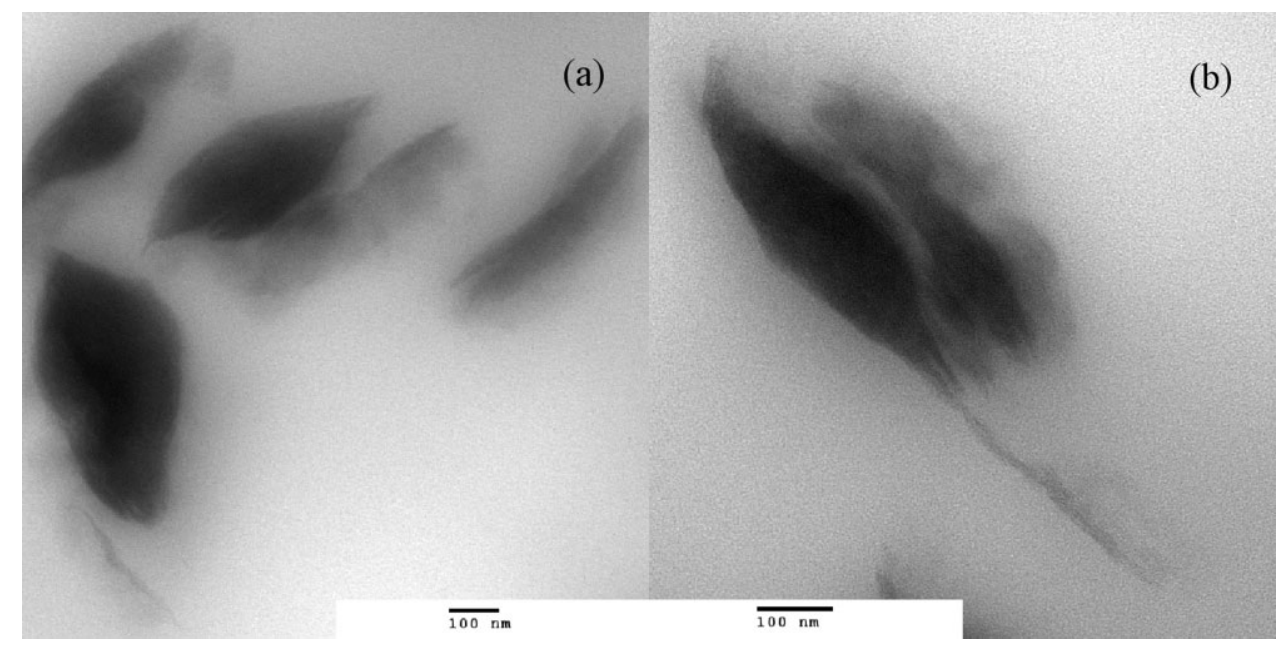

Figure 4 TEM micrographs of edge-treated $\mathrm{ZrP} / \mathrm{PCL}(5 \% \mathrm{w} / \mathrm{w})$ after compounding, extrusion, and molding: (a) edge peeling and (b) shear delamination of a tactoid's outer surface. 


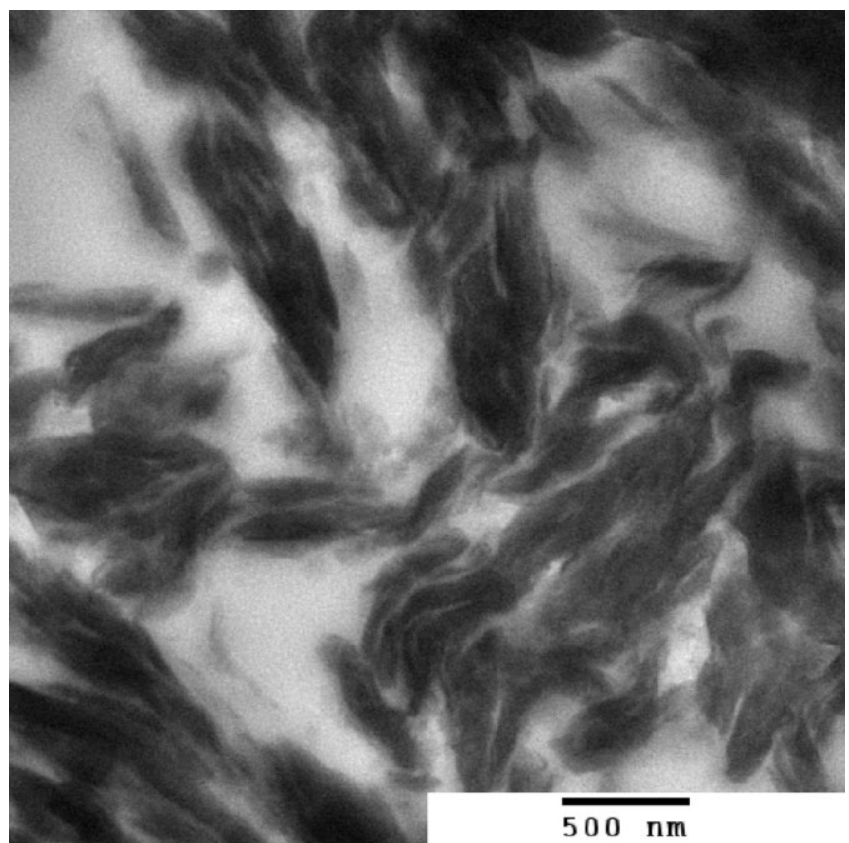

Figure 5 TEM micrographs of $50 \% \mathrm{w} / \mathrm{w}$ edge-treated $\mathrm{ZrP}$ in PCL after compounding, extrusion, and molding. $\mathrm{ZrP}$ tactoids appear intact despite being distorted by shear flow.

they were separated from the dispersed $\mathrm{ZrP}$ tactoids, rather than forced apart by swelling from within. Intercalation was not detected by increased $d$-spacings in XRD and did not appear to serve a role in the delamination of the tactoids.

In $\mathrm{ZrP} / \mathrm{PCL}$ loaded at $50 \% \mathrm{w} / \mathrm{w}$, the aggregates were so crowded together that exfoliation or drawing by the matrix polymer was entirely prevented. The tactoids tended to coalesce rather than shear one another apart (Fig. 5).

It is possible that the acetone used to aid mixing via the SpeedMixer method also aided in the swelling of $\mathrm{ZrP}$. The mixer is capable of combining very viscous materials, but it cannot develop high shear in materials that do not flow at all. Acetone was found empirically to be the most efficient solvent for plasticizing PCL and may prove to be a useful processing aid.

\section{Nanocomposite mechanical characterization: tensile properties}

Extruded fibers were tested in uniaxial tension with the goal of determining the ultimate properties and also gaining a measure of the fracture energy. A summary of the ultimate properties is given in Table I. Young's modulus was determined from the linear portion of the stress-strain response, which typically occurred in the strain range of $0.01-0.03$.

The yield strength of the $5 \% \mathrm{w} / \mathrm{w} \mathrm{ZrP} / \mathrm{PCL}$ nanocomposite was significantly increased $(P=0.01)$ by an average of $8 \%$ over that of the base polymer.
However, the nanocomposite yield strengths were reduced with higher $\mathrm{ZrP}$ loadings. The tensile elastic moduli of all nanocomposites were significantly higher $(P<0.05)$ than that of unmodified PCL. Only the $50 \% \mathrm{w} / \mathrm{w} \mathrm{ZrP}$ sample was significantly stiffer than the other nanocomposite groups, whose average improvement was $24 \%$. Therefore, the use of more than 5\% octyl/MOUD $\mathrm{ZrP}$, as prepared in this study, is not recommended for improving the ultimate properties of PCL unless the application favors elastic modulus over yield strength.

The tensile characteristics of PCL nanocomposites were previously investigated with LS fillers. ${ }^{30-32}$ Ductility (ca. $800 \%$ elongation) was maintained with up to $7.5 \% \mathrm{w} / \mathrm{w}$ Cloisite 30B in compression-molded PCL nanocomposites, whereas the tensile modulus increased by $67 \%$ and the yield strength declined by $27 \% .{ }^{30}$ The ductility of PCL was severely compromised with $10 \% \mathrm{w} / \mathrm{w}$ or more intercalated montmorillonite (equivalent to $4.4 \% \mathrm{v} / \mathrm{v}$ ). ${ }^{31}$ In comparison, our materials showed less improvement in the elastic modulus with better retention of the yield strength, and this suggested less interaction between the polymer and the $\mathrm{ZrP}$ tactoids in comparison with fully intercalated layered silicate (LS).

The total work of fracture, defined as the area under the load-displacement curve, could not be assessed for specimens containing up to $20 \% \mathrm{w} / \mathrm{w}$ $\mathrm{ZrP}(\approx 15 \% \mathrm{v} / \mathrm{v})$ because they did not fracture within the limits of the test frame, that is, $650 \%$ elongation. This result compares favorably with the results for intercalated montmorillonite/PCL nanocomposites, whose extensibility decreased from 550 to $350 \%$ with an increase in the filler loading from $10(\approx 4.4 \% \mathrm{v} / \mathrm{v})$ to $20 \% \mathrm{w} / \mathrm{w} \cdot{ }^{31}$ However, specimens containing $50 \% \mathrm{w} / \mathrm{w} \mathrm{ZrP}$ were exceedingly brittle, and the fracture toughness was better quantified by SENB testing.

\section{Flexural properties}

Flexural testing was carried out to elucidate any differences between the elastic moduli of the

TABLE I

Tensile Testing Data for Extruded Fibers $(n=7)$

\begin{tabular}{lccl}
\hline \multicolumn{1}{c}{ Sample } & $\begin{array}{c}\text { Tensile } \\
\text { yield stress } \\
(\mathrm{MPa})\end{array}$ & $\begin{array}{c}\text { Tensile elastic } \\
\text { modulus } \\
(\mathrm{MPa})\end{array}$ & $\begin{array}{c}\text { Elongation } \\
(\%)\end{array}$ \\
\hline PCL & $15.6 \pm 1.2$ & $226 \pm 30$ & $>650$ \\
PCL $+5 \% \mathrm{ZrP}$ & $16.9 \pm 0.3$ & $277 \pm 38$ & $>650$ \\
PCL $+10 \% \mathrm{ZrP}$ & $14.5 \pm 0.8$ & $294 \pm 35$ & $>650$ \\
PCL $+15 \% \mathrm{ZrP}$ & $14.7 \pm 0.7$ & $299 \pm 12$ & $>650$ \\
PCL $+20 \% \mathrm{ZrP}$ & $14.4 \pm 0.8$ & $318 \pm 42$ & $>650$ \\
PCL $+50 \% \mathrm{ZrP}$ & $11.0 \pm 3.7$ & $495 \pm 101$ & $<6$ \\
\hline
\end{tabular}

Tensile values plus or minus 1 standard deviation are shown. 
TABLE II

Flexural and Storage Moduli with Random-Error Probabilities for Molded Beams Tested in Pseudostatic and Dynamic (1 Hz) Three-Point Bending at $25^{\circ} \mathrm{C}$

\begin{tabular}{lcccc}
\hline \multicolumn{1}{c}{ Sample } & $\begin{array}{c}\text { Flexural } \\
\text { modulus } \\
(\mathrm{MPa})\end{array}$ & $P$ & $\begin{array}{c}\text { Storage } \\
\text { modulus } \\
(\mathrm{MPa})\end{array}$ & $P$ \\
\hline $\mathrm{PCL}$ & $256 \pm 13$ & - & $320 \pm 29$ & - \\
$\mathrm{PCL}+5 \% \mathrm{ZrP}$ & $310 \pm 65$ & 0.282 & $360 \pm 38$ & 0.151 \\
$\mathrm{PCL}+10 \% \mathrm{ZrP}$ & $358 \pm 23$ & 0.005 & $486 \pm 46$ & 0.010 \\
$\mathrm{PCL}+15 \% \mathrm{ZrP}$ & $332 \pm 41$ & 0.073 & $469 \pm 91$ & 0.002 \\
PCL $+20 \% \mathrm{ZrP}$ & $359 \pm 17$ & 0.001 & $464 \pm 15$ & 0.005
\end{tabular}

Modulus values plus or minus 1 standard deviation (n $=3$ ) are shown

nanocomposites that were not detected during tensile testing. Furthermore, a comparison was made between the Young's moduli and the dynamic storage moduli obtained at the same temperature. The results are summarized in Table II.

There was a significant increase in the quasistatic flexural moduli of the 10 and $20 \%$ filled experimental groups versus the unfilled control. However, none of the experimental groups was significantly different from any other $(P<0.05)$ in this testing mode. The DMA data show a similar trend. However, the 10 and $20 \%$ filled materials had significantly higher storage moduli than both the control and the $5 \% \mathrm{ZrP}$ composite. The overall variability was high, suggesting the need for more specimens to obtain greater statistical power.

\section{Fracture toughness}

SENB specimens containing 0 or $20 \% \mathrm{w} / \mathrm{w} \mathrm{ZrP}$ failed in a fully plastic manner, that is, with extensive crack-tip blunting and without crack extension. Therefore, fracture toughness values could not be calculated for the material. Typical load-displacement curves are shown in Figure 6. Within the limits of the test displacement, the $20 \%$ filled material exhibited a greater area under the load-displacement curve, which suggested a greater resistance to crack propagation consistent with particle reinforcement. Specimens containing $50 \% \mathrm{w} / \mathrm{w}$ failed in a more brittle manner with crack-tip blunting and crack extension so that the fracture toughness could be determined by Rice's J-integral approach from elastic-plastic fracture mechanics. ${ }^{35}$ The mean fracture toughness was $0.64 \mathrm{MPa}\left(\mathrm{m}^{2}\right)$ by this method with a standard deviation of $0.19 \mathrm{MPa}\left(\mathrm{m}^{2}\right)(\mathrm{n}=3)$, which is comparable to a fracture toughness of $0.69-$ $0.91 \mathrm{MPa}\left(\mathrm{m}^{2}\right)$ for ZrP-filled epoxy nanocomposites. $^{22}$ This fracture toughness $\left(0.64 \mathrm{MPa}\left(\mathrm{m}^{2}\right)\right)$ is higher than that of a brittle thermoset, such as a cured epoxy or dimethacrylate resin, but it repre- sents both a substantial embrittlement of the base thermoplastic and a critical transition in the failure mechanism in comparison with the lower filled PCL specimens. A possible failure mechanism responsible for the low fracture toughness may be delamination along the $\mathrm{ZrP}$ lamellar interfaces. ${ }^{22}$

\section{DMA}

Beam specimens were independently tested for their responses to changes in the temperature and loading frequency. Data from the thermal scans are plotted in Figure 7, whereas the frequency spectra are shown in Figure 8.

The onset of the glass transition in PCL was below the tested temperature range; however, the $\tan \delta$ response peaked at $-22^{\circ} \mathrm{C}$ in Figure 7. The literature-reported value of $T_{g}$ is $-60^{\circ} \mathrm{C}$ for PCL with a number-average molecular weight up to $42,500{ }^{36}$ Such low-temperature responses could not be reproduced in this study, but the doubling of the molecular weight may account for the apparent increase in $T_{g}$ observed here.

In DMA, the onset of melting shifted to lower temperatures with increasing $\mathrm{ZrP}$. A correlated downward trend in the melting temperature with increasing filler was observed in DSC (Fig. 9); however, the onset and peak melting temperatures were not significantly different for any of the studied loading levels $(P>0.05)$. The peak values were in agreement with the previously reported melting range for $\mathrm{PCL}$, which is $59-64^{\circ} \mathrm{C}^{36}$ The heat of melting was significantly reduced for $50 \% \mathrm{w} / \mathrm{w} \mathrm{ZrP}$ $(P=0.01)$. This yielded a reduction in crystallinity from 48 to $29 \%$ based on a value of $136 \mathrm{~J} / \mathrm{g}$ for $100 \%$ crystalline $\mathrm{PCL}^{37}$ (see Fig. 9). Disturbances in the

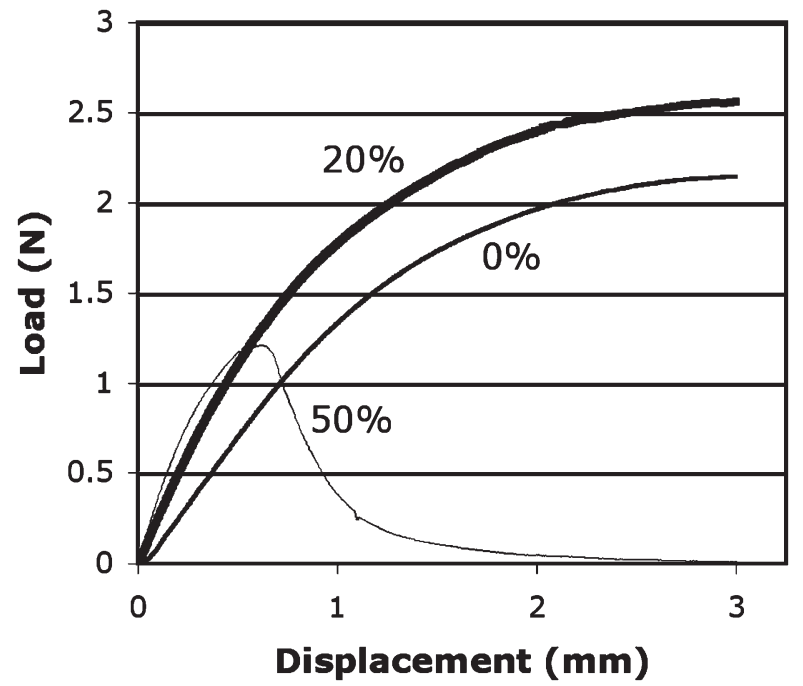

Figure 6 Representative load-displacement curves for SENB specimens at various $\mathrm{ZrP}$ filler loadings $(\mathrm{w} / \mathrm{w})$. 

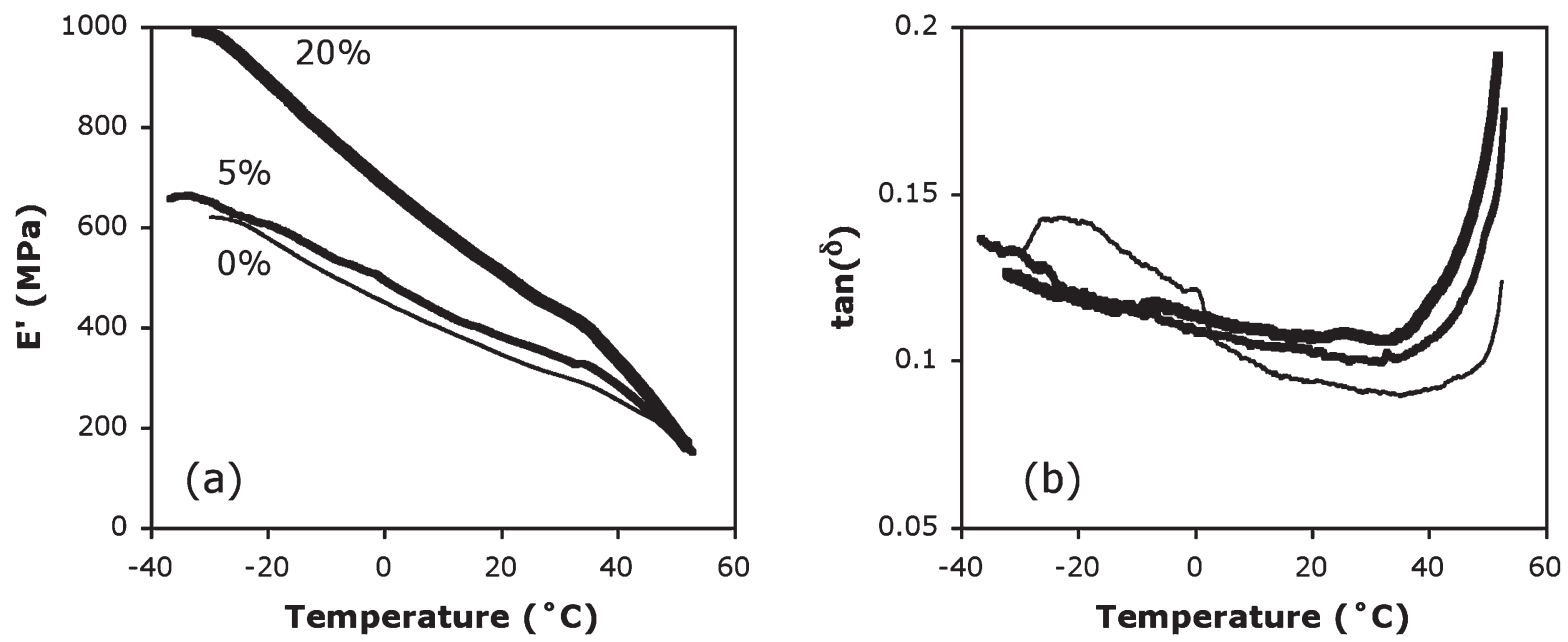

Figure 7 Thermal spectra for (a) the storage modulus $\left(E^{\prime}\right)$ and (b) tan $\delta$ for $0 \%, 5 \%$, and 20\% w/w ZrP/PCL materials loaded at a frequency of $1 \mathrm{~Hz}(\mathrm{n}=3)$. Increased stiffness, quenching of the glass transition, and reduced melting onset in the filled samples are shown.

crystalline morphology of the PCL, such as altered crystallite size, were not apparent from the wideangle XRD data presented in Figure 3. Therefore, the crystallinity of the PCL matrix appeared largely unaffected by the presence of $\mathrm{ZrP}$ tactoids. This is consistent with observations for LS nanoparticles, whose thorough exfoliation is required to nucleate smaller crystallites. ${ }^{38}$

There was a meaningful increase in the storage modulus after the addition of as little as $5 \% \mathrm{w} / \mathrm{w}$ $\mathrm{ZrP}$, and the glass transition appeared to be completely quenched. The increase in the storage modulus indicates that the $\mathrm{ZrP}$ does not have a plasticizing effect. This suggests that there is good adhesion between the tactoids and the matrix. Furthermore, the apparent loss of $T_{g}$ (Fig. 7) is attributable to a shift above the melting temperature, rather than to a lower temperature, due to the rigidifying effect of the filler. The crossover point for the storage

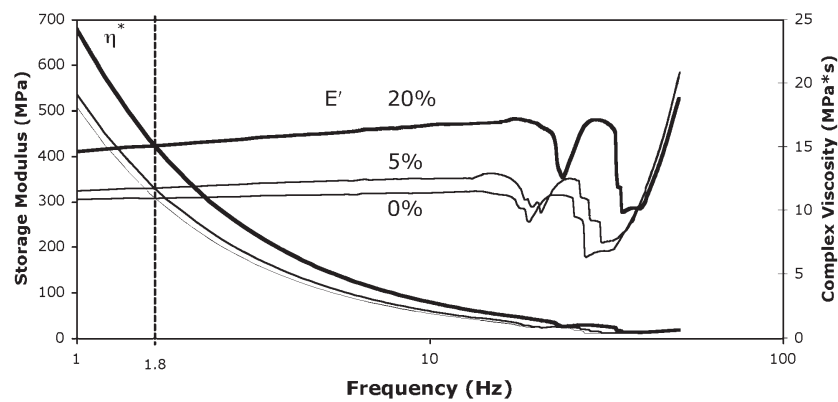

Figure $8 \quad \log _{10}$ frequency plots for $\mathrm{ZrP} / \mathrm{PCL}$ at different weight fractions. The intersection of the complex viscosity $\left(\eta^{*}\right)$ and storage modulus $\left(E^{\prime}\right)$ at $1.8 \mathrm{~Hz}(\mathrm{n}=3)$ is shown. Characteristic relaxation frequencies increase as the filler level increases. modulus and complex viscosity curves in the frequency spectra (Fig. 8) was identical between the nanocomposites and the PCL control, and this suggested that the effective molecular weight was not altered through physical crosslinking. ${ }^{39,40}$

\section{CONCLUSIONS}

Delamination of octyl/MOUD ZrP was very limited in the studied formulations despite careful surface design $^{24}$ and preparation and the use of high-shear blending equipment. Delamination in $\mathrm{ZrP} / \mathrm{PCL}$ occurred principally by shearing action between the polymer and the dispersed tactoids and not by intercalative penetration of the tactoids. The thermodynamic interactions between the polymer and the basal nanoplatelet surfaces were therefore insufficient to drive intercalation.

A mobile solvent may be required to overcome kinetic barriers to intercalation. Evidence of a

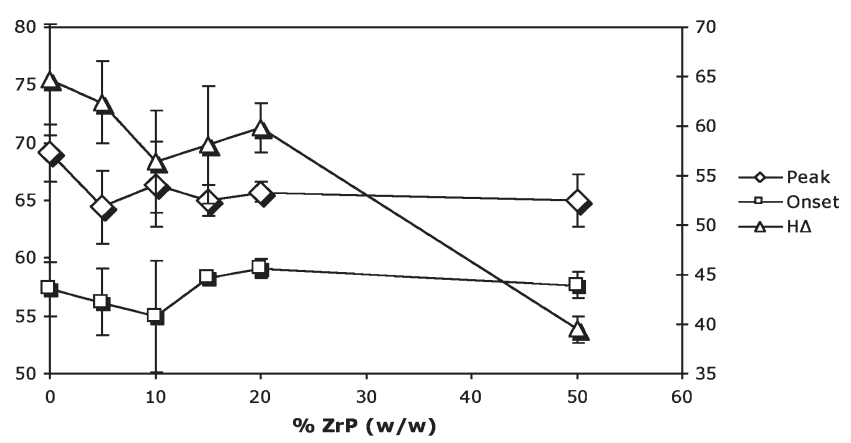

Figure 9 Melt behavior of ZrP-filled PCL as determined from DSC experiments. Error bars are \pm 1 standard deviation $(n=3)$. 
beneficial solvent-swelling effect was seen in the SpeedMixer-formulated blend processed with acetone. Diffusional aids such as sonication may also be helpful. Unlike LS platelets, the acidic edges of ZrP materials cannot be silanated. Quaternary ammonium species can provide hydrophobicity to the dangling $\equiv \mathrm{PO}^{-}$bonds populating the nanoplatelet edges. Although TEAH proved insufficient to promote intercalation in this study, longer chain and mixed-tail compounds should be investigated.

Dispersed ZrP tactoids, about $100 \mathrm{~nm}$ in breadth, served as a useful reinforcement phase in PCL at the $5 \% \mathrm{w} / \mathrm{w}(\approx 3.8 \% \mathrm{v} / \mathrm{v})$ level despite minimal exfoliation of the nanoplatelet system. The yield strength and tensile modulus of the material were improved without a substantial reduction of the polymer's ductility. Layered tactoids exhibited tortuosity when combined with PCL under high-shear melt conditions. Such distortions suggest that the tactoids have the ability to undergo interlamellar shear deformation in response to the surrounding polymer despite the general coherence of the layers. The lengthening of the tactoids provided a minor improvement in the effective particle aspect ratio, and this helped to explain the improved properties of the $5 \% \mathrm{ZrP} / \mathrm{PCL}$ system. Crowding and agglomeration became prevalent as the tactoid level increased, resulting in defect structures and a loss of mechanical properties.

The authors are grateful to Don Moravits and Jason Patton (Southwest Research Institute) for their assistance with the mechanical testing and also to Lauren Chesnut, Barbara Hunter, and Erin Manitou (Department of Pathology, University of Texas Health Science Center at San Antonio) for their assistance with sectioning of the TEM samples.

\section{References}

1. Murakami, A.; Saunders, D.; Ooishi, K.; Yoshiki, T.; Saitoo, M.; Watanabe, O.; Takezawa, M. J Adhes 1992, 39, 227.

2. Hodgkin, J. H.; Simon, G. P.; Varley, R. J. Polym Adv Technol 1998, 9, 3.

3. Fisher, F. T.; Brinson, L. C. Compos Sci Technol 2001, 61, 731.

4. Alexandre, M.; Dubois, P. Mater Sci Eng R 2000, 28, 1.

5. Giannelis, E. P.; Krishnamoorti, R.; Manias, E. Adv Polym Sci 1999, 138, 107.

6. Theng, B. K. G. The Chemistry of Clay-Organic Reactions; Wiley: New York, 1974.

7. Ogawa, M.; Kuroda, K. Bull Chem Soc Jpn 1997, 70, 2593.

8. Paul, D. Presented at the MRS 2002 Spring Meeting, San Francisco, CA, 2002.
9. Es, M. V.; Xiqiao, F.; Turnhout, J. V.; Giessen, E. V. D. In Specialty Polymer Additives; Al-Malaika, S.; Golovoy, A.; Wilke, C. A., Eds.; Blackwell Science: Oxford, 2001; Chapter 21.

10. Nielsen, L. E.; Landel, R. F. Mechanical Properties of Polymers and Composites; Marcel Dekker: New York, 1994.

11. Wang, J.; Pyrz, R. Compos Sci Technol 2004, 64, 935.

12. Pinnavaia, T. J.; Beall, G. W. In Polymer-Clay Nanocomposites; Scheirs, J., Ed.; Wiley: New York, 2000.

13. Vaia, R. A.; Giannelis, E. P. Macromolecules 1997, 30, 7990.

14. Scheutjens, J. M. H. M.; Fleer, G. J Phys Chem 1980, 84, 178.

15. Fleer, G.; Cohen-Stuart, M. A.; Scheutjens, J. M. H. M. Polymers at Interfaces; Chapman \& Hall: London, 1993.

16. Balazs, A.; Ginzburg, V. V.; Lyatskaya, Y.; Singh, C.; Zhulina, E. In Polymer-Clay Nanocomposites; Pinnavaia, T. J.; Beall, G. W., Eds.; Wiley: New York, 2000; p 281.

17. Kim, G.-M.; Lee, D.-H.; Hoffmann, B.; Kressler, J.; Stöppelmann, G. Polymer 2001, 42, 1095.

18. Liu, L. M.; Qi, Z. N.; Zhu, X. G. J Appl Polym Sci 1999, 71, 1133.

19. Shia, D.; Hui, C. Y.; Burnside, S. D.; Giannelis, E. P. Polym Compos 1998, 19, 608.

20. Manias, E.; Touny, A.; Wu, L.; Strawhecker, K.; Lu, B.; Chung, T. C. Chem Mater 2001, 13, 3516.

21. Sun, L.; Boo, W. J.; Sun, D.; Clearfield, A.; Sue, H.-J. Chem Mater 2007, 19, 1749.

22. Sue, H.-J.; Gam, K. T.; Bestaoui, N.; Spurr, N.; Clearfield, A. Chem Mater 2004, 16, 242.

23. Sue, H.-J.; Gam, K. T.; Bestaoui, N.; Clearfield, A.; Miyamoto, M.; Miyatake, N. Acta Mater 2004, 52, 2239.

24. Furman, B. R.; Wellinghoff, S. T.; Thompson, P. M.; Beall, G. W.; Laine, R. M.; Rawls, R. H. Chem Mater 2008, 20, 5491.

25. Kweon, H. Y.; Yoo, M. K.; Park, I. K.; Kim, T. H.; Lee, H. C.; Lee, H. S.; Oh, J. S.; Akaike, T.; Cho, C. S. Biomaterials 2003, 24, 801.

26. Alberti, G.; Costatino, U.; Tomassini, A. S. N. J Inorg Nucl Chem 1978, 40, 1113.

27. Furman, B. R. Materials Science and Engineering; University of Michigan: Ann Arbor, MI, 2007; p 179.

28. Poojary, M. D.; Hu, H.-L.; Campbell, F. L., III; Clearfield, A. Acta Crystallogr B 1993, 49, 996.

29. Clearfield, A.; Smith, G. D. Inorg Chem 1968, 8, 431.

30. Ludueña, L. N.; Alvarez, V. A.; Vazquez, A. Mater Sci Eng A 2007, 460, 121.

31. Chen, B.; Evans, J. R. G. Macromolecules 2006, 39, 747.

32. Homminga, D.; Goderis, B.; Hoffman, S.; Reynaers, H.; Groeninckx, G. Polymer 2005, 46, 9941.

33. Massenelli-Varlot, K.; Vigier, G.; Vermogen, A.; Gauthier, C.; Cavaillé, J. Y. J Polym Sci Part B: Polym Phys 2007, 45, 1243.

34. Cotterell, B.; Chia, J. Y. H.; Hbaieb, K. Eng Fract Mech 2007, 74,1054

35. Meyers, M. A.; Chawla, K. K. Mechanical Behavior of Materials; Prentice Hall: New York, 1998.

36. Sinha, V. R.; Bansal, K.; Kaushik, R.; Kumria, R.; Trehan, A. Int J Pharm 2004, 278, 1.

37. Lepoittevin, B.; Devalckenaere, M.; Pantoustier, N.; Alexandre, M.; Kubies, D.; Calberg, C.; Jerome, R.; Duboi, P. Polymer 2002, 43, 4017.

38. Ray, S.; Yamada, K.; Okamoto, K.; Fujimoto, Y.; Ogami, A.; Ueda, K. Chem Mater 2003, 15, 1456.

39. Menard, K. Dynamic Mechanical Analysis: A Practical Introduction; CRC: New York, 1999.

40. Macosko, C. Rheology; VCH: New York, 1996. 